\title{
ROUND AND ROUND AND UP AND DOWN: TRILOBITE TAPHONOMY OF A LOWER SILURIAN REEF LIMESTONE
}

RUDKIN*, David M., Department of Invertebrate Palaeontology, Royal Ontario Museum, 100 Queen's Park, Toronto, Ontario, Canada M5S 2C6; WESTROP, Stephen R., Department of Earth Sciences, Brock University, St. Catharines, Ontario, Canada L2S 3A1

Trilobites on and adjacent to exhumed reefs of the Late Llandoverian Attawapiskat Formation, northern Ontario, occur as monospecific to low diversity accumulations that display extensive taphonomic sorting. Most spectacular are "nests" of pygidia of the large scutelluine trilobite Ekwanoscutellum ekwanensis (Whiteaves) that often comprise more than 50 individual sclerites stacked several deep, and cover areas of up to a square metre. Size and orientation data for more than 400 specimens in 19 "nests" indicate that virtually all pygidia are inverted (concave-up), yet axial azimuth and anterior/posterior orientations appear to be entirely random. This is consistent with passive settling of pygidia in "current shadows" in the lee of obstacles in this high-energy reef system. Size-frequency distributions cluster tightly around a single size class. This pattern may reflect size-sorting of sclerites by currents prior to their eventual deposition.

Alternatively, the narrow range of sizes could reflect behavioral factors, such as synchronous moulting.

Other dominant trilobite species have different occurrences. For example, convex, effaced cranidia and pygidia of the illaenid Stenopareia julli Norford occur most abundantly in brachiopod-rich bioclastic rudstones that may represent higher energy channel deposits. Sclerites of the small scutelluine Meroperix aquilonaris (Whiteaves) also occur commonly in these rudstones but are seldom found in association with Ekwanoscutellum. Species of at least eight additional genera are less abundant and show no consistent distributional patterns.

The data underscore the taphonomic complexity of patchy environments such as Silurian reefs and indicate that extensive sorting of skeletons is a significant source of bias in paleoecologic analysis of vagile components of reef biofacies. 